\title{
Long-term outcomes after radical or partial nephrectomy for T1a renal cell carcinoma: A population-based study
}

Madhur Nayan, MD, CM, $\mathrm{PhD}^{1}$; Olli Saarela, $\mathrm{PhD}^{2}$; Keith Lawson, $\mathrm{MD}^{1}$; Lisa Martin, $\mathrm{PhD}^{1}$; Maria Komisarenko, $\mathrm{MSc}^{1}$; Antonio Finelli, MD, $\mathrm{MSc}^{1}$

${ }^{1}$ Division of Urology, Departments of Surgery and Surgical Oncology, Princess Margaret Cancer Centre, University Health Network and the University of Toronto, Toronto, ON, Canada; ${ }^{2}$ Dalla Lana School of Public Health, University of Toronto, Toronto, ON, Canada

An abstract of this study was presented as a podium presentation at the 2019 American Urological Association Meeting in Chicago, IL, U.S., and as a moderated poster at the 2019 Canadian Urological Association Meeting in Quebec City, QC, Canada

Cite as: Can Urol Assoc J 2020 June 16; Epub ahead of print. http://dx.doi.org/10.5489/cuaj.6343

Published online June 16, 2020

$* * *$

\section{Abstract}

Introduction: The benefit of partial nephrectomy (PN) compared to radical nephrectomy (RN) for T1a renal cell carcinoma (RCC) remains uncertain, with observational studies conflicting with level 1 evidence. Therefore, the purpose of this population-based study was to compare long-term outcomes in patients undergoing PN or RN for T1a RCC.

Methods: We studied 5670 patients in Ontario, Canada undergoing PN or RN for T1a RCC. The primary outcome was overall survival (OS). Secondary outcomes were cancer-specific survival (CSS), chronic kidney disease (CKD), end-stage renal disease (ESRD), and myocardial infarction (MI). We used multivariable Cox proportional hazard models to evaluate the association between PN or RN and these outcomes. A sensitivity analysis was performed in patients with a preoperative serum creatinine available.

Results: Median followup was 77 months. Compared to RN, PN was associated with significantly improved OS (hazard ratio [HR] 0.73; 95\% confidence interval [CI] 0.63-0.84), reduced risk of CKD (HR 0.18; 95\% CI 0.12-0.27) and improved CSS (HR 0.45; 95\% CI 0.300.65). The risk of myocardial infarction was not significantly different between groups (HR 0.91; 95\% CI 0.62-1.34). Few patients $(n=15)$ required renal replacement therapy. In the sensitivity analysis, the association between type of surgery and OS and CKD persisted, while the association with CSS did not. 
Conclusions: Our study found that in patients undergoing surgery for T1a RCC, PN was associated with improved OS and reduced risk of CKD compared to RN. However, few patients in either group developed ESRD requiring renal replacement therapy.

\section{Introduction}

The incidence of kidney cancer is increasing in several countries ${ }^{1}$. This increase is thought to be due to the rising prevalence of obesity and hypertension, both of which are established risk factors for kidney cancer ${ }^{2}$, and the increased use of diagnostic imaging ${ }^{3}$. The increased use of diagnostic imaging may explain the stage migration that has been observed over time, with the vast majority of tumours detected in the modern era being stage T1a tumours (tumours less than $4 \mathrm{~cm})^{4}$.

Several guidelines recommend that patients with clinical stage T1a tumours be managed preferentially with partial nephrectomy $(\mathrm{PN})$ over radical nephrectomy $(\mathrm{RN})^{5-7}$. This recommendation is based on several observational studies demonstrating that $\mathrm{PN}$ is associated with a reduced risk of renal dysfunction and improved overall survival compared to $\mathrm{RN}^{8}$. However, many of these observational studies have been limited by sample size, follow-up, and inclusion of patients with heterogenous kidney cancer characteristics. Furthermore, few have been population-based, limiting their generalizability. The only randomized trial comparing these surgical approaches validated the increased risk of renal dysfunction with $\mathrm{RN}^{9}$; however, overall survival in this trial was improved in the $\mathrm{RN}$ arm ${ }^{10}$.

Given that the therapeutic benefit of $\mathrm{PN}$ remains uncertain ${ }^{8}$ in patients presenting with clinical stage T1a kidney cancer, the most common stage of presentation in the present era, we performed a population-based study evaluating long-term survival and renal disease following $\mathrm{PN}$ compared to $\mathrm{RN}$ in these patients.

\section{Methods}

\section{Setting and design}

We performed a population-based cohort study of kidney cancer patients undergoing nephrectomy for stage T1a kidney cancer between 1995 and 2014 using linked administrative databases from Ontario, Canada. Our study was approved by the Research Ethics Board at the University Health Network, Toronto, Ontario, Canada.

\section{Data sources}

We used the Canadian Institute for Health Information Discharge Abstract Database, Same Day Surgery Database, National Ambulatory Care Reporting System, and Ontario Health Insurance Plan databases to obtain information on use of health-care services and hospitalizations, the Ontario Cancer Registry to obtain information on cancer diagnosis date and cause of death, 
where applicable, and the Registered Person's Database to obtain patient demographics including date of birth, gender, place of residence via postal code, and date of death. We abstracted pathology records from Cancer Care Ontario, and linked them with the administrative database records. Several of these databases have been validated and have been described in detail elsewhere ${ }^{11}$.

\section{Study patients}

To derive a cohort of patients undergoing a single nephrectomy for stage Tla renal cell carcinoma, we first identified hospitalizations containing a record for a PN or RN. We then linked these records with the Ontario Cancer Registry and only records with a kidney cancer diagnosis date within 14 days of nephrectomy date were kept. These records were linked to abstracted pathology reports, which contained information on histology and tumour size, and only records with histology consistent with renal cell carcinoma and maximal tumour size $\leq$ $4.0 \mathrm{~cm}$ were kept. To compare only a single partial vs. radical nephrectomy, we further excluded patients with any nephrectomy prior to or following the initial nephrectomy for kidney cancer.

\section{Assessment of exposure}

The type of nephrectomy, PN vs. RN, was based on the recorded procedure code during the relevant hospitalization. The date of nephrectomy was considered the index date.

\section{Assessment of outcomes}

The primary outcome was overall survival, defined as the time from the date of nephrectomy to death from any cause, or December $31^{\text {st }}, 2016$, whichever came first. The secondary outcomes were time to diagnosis of chronic kidney disease (CKD), defined as time from nephrectomy to date of CKD diagnosis, or March $31^{\text {st }}, 2015$, whichever came first; time to renal replacement therapy, defined as time from nephrectomy to first hospitalization code for kidney transplant or dialysis, or March $31^{\text {st }}, 2015$, whichever came first; time to myocardial infarction, defined as time from nephrectomy to date of myocardial infarction diagnosis, or March $31^{\text {st }}, 2015$, whichever came first; and cancer-specific mortality, defined as time from nephrectomy to death from kidney cancer, or December $31^{\text {st }}, 2011$, whichever came first. Deaths within 30 days of nephrectomy were attributed to death from kidney cancer ${ }^{12}$. The end dates were chosen based on the last update for the relevant databases at the time that the study cut-off date.

\section{Statistical analysis}

We compared baseline characteristics using standardized differences, whereby a threshold of $>0.10$ indicated a significant difference ${ }^{13}$. We conducted time-to-event analysis using multivariable Cox proportional hazard regression to estimate the association of type of nephrectomy on the risk of the primary and secondary outcomes. The proportional hazards assumption was verified by evaluating Schoenfield residuals ${ }^{14}$. For the secondary outcomes, we estimated the cause-specific hazard as we were interested in understanding the potential etiology of kidney cancer survival outcomes related to type of nephrectomy ${ }^{15}$. Covariates in the 
multivariable model were chosen a priori and included age, income quintile, Charlson score, year of surgery, tumour size, and histology. We confirmed the absence of significant collinearity based on the variance inflation factor ${ }^{16}$. For the renal function outcomes, we excluded patients with any previous history of diabetes, hypertension, CKD, or renal replacement therapy to avoid potential bias of preferential use of partial nephrectomy based on specific comorbidities.

All statistical analyses were performed using SAS (version 9.3; SAS Institute, Cary, NC).

\section{Sensitivity analysis}

We repeated the analyses adjusting for serum creatinine within one year prior to nephrectomy in patients in whom this data was available.

\section{Results}

A total of 5,670 patients met the inclusion criteria, of which 3,167 (55.9\%) underwent $\mathrm{RN}$ and 2,503 (44.1\%) underwent PN (Table 1). Other than income quintile, all other baseline characteristics were significantly different between the PN and RN groups. The analyses for the renal function outcomes included 2,110 patients.

\section{Primary outcome}

Median follow-up for overall survival was 77 months, during which there were 1,187 deaths, 260 in the PN group and 927 in the RN group. Compared to RN, PN was associated with significantly improved overall survival (hazard ratio (HR) $0.73,95 \%$ confidence interval (CI) 0.63 to 0.84 ), supplemental table).

\section{Secondary outcomes}

The results for the secondary outcomes are summarized in Table 2 and detailed in the supplemental table. Multivariable Cox proportional hazard models found that compared to RN, PN was associated with significantly reduced risk of CKD (HR 0.18, 95\% CI 0.11 to 0.27 ) and significantly improved cancer-specific mortality (HR $0.45,95 \%$ CI 0.30 to 0.65 ). The risk of myocardial infraction was not significantly different between groups (HR 0.91, 95\% CI 0.62 to 1.34). The number of patients $(n=15)$ requiring renal replacement therapy was limited, precluding multivariable analysis; univariable analysis found that type of surgery was not associated with renal replacement therapy (HR 0.25, 95\% CI $0.06-1.12$ ).

Serum creatinine within 1 year prior to surgery was available in 2,411 (43\%) patients. A multivariable sensitivity analysis further adjusting for pre-operative serum creatinine demonstrated that OS remained significantly improved in the PN group. Due to the limited number of cancerspecific deaths $(n=31)$ and patients diagnosed with CKD $(n=46)$, these models included only type of surgery and serum creatinine as covariates; PN was associated with a reduced risk of CKD (HR 0.09, 95\% CI 0.04 to 0.20) but not improved cancer-specific survival (HR 0.84, 95\% CI 0.42 to 1.72 ). In this sensitivity analysis, only 2 patients were diagnosed with an myocardial infarction, both in the PN group, and 2 patients required renal replacement therapy, 1 in each group. 


\section{Discussion}

This population-based study spanning nearly 20 years found that compared to RN, PN for T1a kidney cancer was associated with significantly improved overall-survival and reduced risk of CKD. The association with cancer-specific mortality was inconsistent; type of surgery was not associated with risk of myocardial infarction, and the requirement for renal replacement therapy occurred infrequently in either group. These findings reaffirm the preferred use of partial nephrectomy for stage T1a kidney cancer, when feasible.

To date, EORTC 30904 is the only randomized trial that has compared RN vs. $\mathrm{PN}^{10}$. This multi-centre trial randomized 541 patients with tumours $<5 \mathrm{~cm}$ suspicious for renal cell carcinoma to RN vs. PN. Median follow-up was 9.3 years for overall survival. In the intentionto-treat analysis, $\mathrm{PN}$ was associated with significantly worse overall survival but there was no significant difference in cancer-specific mortality (only $2 \%$ of patients died of cancer). In the subgroup analysis of patients with confirmed renal cell carcinoma histology, the association for overall survival was not statistically significant. This trial also found that cardiovascular deaths were less common in the RN group ${ }^{10}$, RN was favourable in terms of lower perioperative morbidity ${ }^{17}$, while PN provided better renal function outcomes ${ }^{9}$. The results of this trial have been controversial and several criticisms, including premature study closure, cross-over between groups, the design of a non-inferiority trial but the overall survival benefit with $\mathrm{RN}$ being based on a test of superiority, among others, have made it difficult to interpret the results.

Despite the only level 1 evidence on this topic supporting the use of RN over PN for small renal masses, several guidelines recommend the preferential use of PN, when feasible . $^{5-7}$. This is based on the biological rationale and several observational studies demonstrating the benefit of PN over RN. A systematic review and meta-analysis was published in 2012 included 36 studies evaluating 31,729 RN and 9,281 PN patients undergoing surgery for localized kidney cancer $^{18}$. This study found that PN was associated with significantly improved overall survival, improved cancer-specific mortality, and reduced risk of CKD. A more recent meta-analysis also found a reduced risk of CKD associated with $\mathrm{PN}$, but no difference in cardiovascular outcomes between $\mathrm{PN}$ and $\mathrm{RN}^{19}$.

The reduced risk of CKD related to $\mathrm{PN}$ is biologically plausible given the nephronsparing concept behind PN. In our study, the reduced risk of CKD in patients undergoing PN may have contributed to the observed benefit in overall survival. Indeed, the landmark study by Go et. al. found that increasing glomerular filtration rate was inversely associated with risk of death $^{20}$. Their study also found that increasing glomerular filtration rate was inversely associated with cardiovascular outcomes ${ }^{20}$; despite the associated observed benefit in risk of CKD provided by $\mathrm{PN}$ in our study, there was no association with myocardial infarction, consistent with the previously described meta-analysis ${ }^{19}$. This can be explained by the proposed theory that the biology of CKD associated with surgery may be different than that of CKD associated with medical conditions ${ }^{21}$, as those medical conditions, such as diabetes and hypertension, continue to contribute to the risk of cardiovascular outcomes. It is worth noting that the requirement for renal 
replacement therapy occurred infrequently. The results of our large population-based study support a previous analysis of 514 patients from EORTC 30904, which found that only 4 patients in each group developed end-stage renal disease. Put together, these results suggest that although RN likely increases the risk of CKD compared to PN, the risk of end-stage renal disease requiring renal replacement therapy after $\mathrm{RN}$ may be low. Therefore, in select cases, such as those with complex tumours, the risk of PN may outweigh the benefit and $\mathrm{RN}$ remains an option in these select cases for the management of stage T1a kidney cancer.

In the overall cohort, cancer-specific mortality was significantly improved in the PN arm, consistent with the findings of a meta-analysis ${ }^{18}$. This likely represents selection bias as there is no biological rationale supporting $\mathrm{PN}$ as a more oncologic effective procedure. We attempted to reduce selection bias by restricting our cohort to patients with pathologic tumour size $<4 \mathrm{~cm}$ and further adjusting for histology and tumour size; however, the possibility of residual confounding remains. In our sensitivity analysis restricting to patients with pre-operative serum creatinine, there was no association between type of surgery and cancer-specific mortality, though this should be interpreted with caution given the limited number of events.

While several observational studies have compared survival outcomes following RN or PN, our study has several strengths. Our population-based study design in a universal health-care setting improves generalizability. Furthermore, we used regularly updated administrative databases, several of which have been validated, allowing us to accurately capture various outcomes over a prolonged period of time. We also had detailed information on various baseline characteristics allowing us to restrict our study to a homogenous population of patients undergoing a single nephrectomy for renal cell carcinoma tumours $<4 \mathrm{~cm}$, and to further adjust for differences in characteristics between patients undergoing RN or PN. Finally, we did a sensitivity analysis adjusting for pre-operative creatinine; albeit, this information was available in a reduced cohort.

This study is not without limitations. Although we attempted to reduce confounding by adjusting for known prognostic factors, the possibility of residual confounding remains. Additionally, our cohort may have included patients with solitary kidney prior to nephrectomy, though this is expected to be infrequent. We were unable to evaluate additional cancer-related outcomes such recurrence or metastasis as these are difficult to define using administrative databases. Finally, there may be subsets of patients for whom there is no benefit of PN or RN; this was not an objective of this study but is an area of future research given the potential increased risk of perioperative morbidity associated with $\mathrm{PN}^{17,22,23}$.

\section{Conclusions}

Our population-based study of patients undergoing nephrectomy for T1a kidney cancer found that compared to radical nephrectomy, partial nephrectomy was associated with significantly improved overall survival and reduced the risk of chronic kidney disease. However, few patients in either group developed end-stage renal disease requiring renal replacement therapy. These findings reaffirm the preferred use of partial nephrectomy for these patients. 


\section{References}

1. Znaor A, Lortet-Tieulent J, Laversanne M, et al. International variations and trends in renal cell carcinoma incidence and mortality. European urology 2015;67:519-30.

2. Chow W-H, Dong LM, Devesa SS. Epidemiology and risk factors for kidney cancer. Nature Reviews Urology 2010;7:245.

3. Lightfoot N, Conlon M, Kreiger N, et al. Impact of noninvasive imaging on increased incidental detection of renal cell carcinoma. European urology 2000;37:521-7.

4. Kane CJ, Mallin K, Ritchey J, et al. Renal cell cancer stage migration: Analysis of the national cancer data base. Cancer 2008;113:78-83.

5. Ljungberg B, Albiges L, Abu-Ghanem Y, et al. European association of urology guidelines on renal cell carcinoma: The 2019 update. Eur Urol 2019

6. Motzer RJ, Jonasch E, Agarwal N, et al. Kidney cancer, version 2.2017, nccn clinical practice guidelines in oncology. Journal of the National Comprehensive Cancer Network 2017; 15:804-34.

7. Campbell S, Uzzo RG, Allaf ME, et al. Renal mass and localized renal cancer: Aua guideline. The Journal of urology 2017;198:520-9.

8. Pierorazio PM, Johnson MH, Patel HD, et al. Management of renal masses and localized renal cancer: Systematic review and meta-analysis. The Journal of urology 2016;196:989-99.

9. Scosyrev E, Messing EM, Sylvester R, et al. Renal function after nephron-sparing surgery versus radical nephrectomy: Results from eortc randomized trial 30904. European urology 2014;65:372-7.

10. Van Poppel H, Da Pozzo L, Albrecht W, et al. A prospective, randomised eortc intergroup phase 3 study comparing the oncologic outcome of elective nephron-sparing surgery and radical nephrectomy for low-stage renal cell carcinoma. European urology 2011;59:543-52.

11. Nayan M, Macdonald EM, Juurlink DN, et al. Medication use and survival in diabetic patients with kidney cancer: A population-based cohort study. Pharmacological research 2016;113:468-74.

12. Welch HG, Black WC. Are deaths within 1 month of cancer-directed surgery attributed to cancer? Journal of the National Cancer Institute 2002;94:1066-70.

13. Austin PC. Using the standardized difference to compare the prevalence of a binary variable between two groups in observational research. Communications in StatisticsSimulation and Computation 2009;38:1228-34.

14. Schoenfeld D. Partial residuals for the proportional hazards regression model. Biometrika 1982;69:239-41.

15. Lau B, Cole SR, Gange SJ. Competing risk regression models for epidemiologic data. American journal of epidemiology 2009;170:244-56.

16. Hair JF, Anderson RE, Tatham RL, et al. Multivariate data analysis new york. NY: Macmillan 1995

17. Van Poppel H, Da Pozzo L, Albrecht W, et al. A prospective randomized eortc intergroup phase 3 study comparing the complications of elective nephron-sparing surgery and radical nephrectomy for low-stage renal cell carcinoma. European urology 2007;51:1606-15. 
18. Kim SP, Thompson RH, Boorjian SA, et al. Comparative effectiveness for survival and renal function of partial and radical nephrectomy for localized renal tumors: A systematic review and meta-analysis. J Urol 2012;188:51-7.

19. Wang Z, Wang G, Xia Q, et al. Partial nephrectomy vs. Radical nephrectomy for renal tumors: A meta-analysis of renal function and cardiovascular outcomes. Urologic oncology 2016;34:533.e11-.e19.

20. Go AS, Chertow GM, Fan D, et al. Chronic kidney disease and the risks of death, cardiovascular events, and hospitalization. New England Journal of Medicine 2004;351:1296-305.

21. Lane BR, Demirjian S, Derweesh IH, et al. Survival and functional stability in chronic kidney disease due to surgical removal of nephrons: Importance of the new baseline glomerular filtration rate. European urology 2015;68:996-1003.

22. Hadjipavlou M, Khan F, Fowler S, et al. Partial vs radical nephrectomy for t1 renal tumours: An analysis from the british association of urological surgeons nephrectomy audit. BJU international 2016;117:62-71.

23. A comparison of overall survival and perioperative outcomes between partial and radical nephrectomy for ct $1 \mathrm{~b}$ and ct 2 renal cell carcinoma - analysis of a national cancer registry 2018. Elsevier.

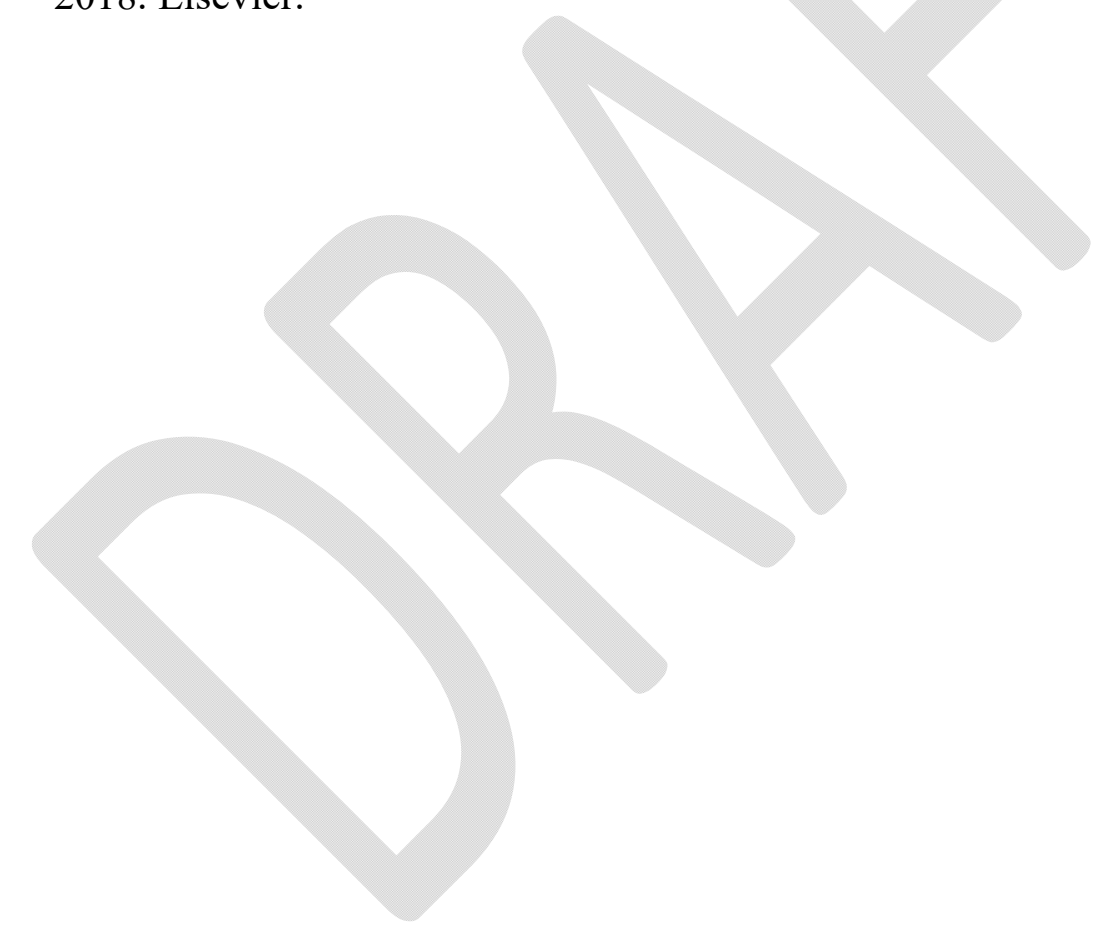


Figures and Tables

\begin{tabular}{|c|c|c|c|}
\hline & $\begin{array}{c}\text { Partial nephrectomy } \\
(n=2503)\end{array}$ & $\begin{array}{c}\text { Radical nephrectomy } \\
(n=3167)\end{array}$ & $\begin{array}{c}\text { Standardized } \\
\text { difference }\end{array}$ \\
\hline $\begin{array}{l}\text { Gender, n (\%) } \\
\text { Female } \\
\text { Male }\end{array}$ & $\begin{array}{c}959(38.3) \\
1544(61.7)\end{array}$ & $\begin{array}{l}1354(42.8) \\
1813(57.3)\end{array}$ & 0.61 \\
\hline $\begin{array}{l}\text { Age group, n (\%) } \\
18-39 \\
40-44 \\
45-49 \\
50-54 \\
55-59 \\
60-64 \\
65-69 \\
70-74 \\
75-79 \\
80+ \\
\end{array}$ & $\begin{array}{c}191(7.6) \\
153(6.1) \\
277(11.1) \\
348(13.9) \\
366(14.6) \\
353(14.1) \\
337(13.5) \\
248(9.9) \\
161(6.4) \\
69(2.8) \\
\end{array}$ & $\begin{array}{c}148(4.7) \\
181(5.7) \\
249(7.9) \\
311(9.8) \\
428(13.5) \\
447(14.1) \\
507(16.0) \\
396(12.5) \\
322(10.2) \\
178(5.6)\end{array}$ & 0.30 \\
\hline $\begin{array}{l}\text { Income quintile, n (\%) } \\
1 \text { (lowest) } \\
2 \\
3 \\
4 \\
5 \text { (highest) } \\
\end{array}$ & $\begin{array}{l}442(18) \\
504(20) \\
500(20) \\
515(21) \\
542(22) \\
\end{array}$ & $\begin{array}{l}632(20) \\
679(21) \\
647(20) \\
613(19) \\
596(19) \\
\end{array}$ & 0.09 \\
\hline $\begin{array}{l}\text { Charlson score, median } \\
\text { (interquartile range) }\end{array}$ & $2(2-3)$ & $2(2-3)$ & 0.15 \\
\hline \begin{tabular}{|l} 
Year of surgery, n (\%)) \\
$1995-2000$ \\
$2001-2005$ \\
$2006-2010$ \\
$2011-2014$ \\
\end{tabular} & $\begin{array}{c}144(6) \\
232(9) \\
790(32) \\
1337(53) \\
\end{array}$ & $\begin{array}{l}876(28) \\
520(16) \\
979(31) \\
792(25) \\
\end{array}$ & 0.78 \\
\hline $\begin{array}{l}\text { Tumour size, median } \\
\text { (interquartile range) }\end{array}$ & $2.5(2.0-3.2)$ & $3.0(2.5-3.6)$ & 0.61 \\
\hline $\begin{array}{l}\text { Histology, n (\%) } \\
\text { Clear-cell } \\
\text { Papillary } \\
\text { Chromophobe } \\
\text { Other }\end{array}$ & $\begin{array}{c}1817(73) \\
527(17) \\
157(6) \\
102(4)\end{array}$ & $\begin{array}{c}2510(79) \\
402(13) \\
150(5) \\
105(3)\end{array}$ & 0.16 \\
\hline
\end{tabular}




\begin{tabular}{|c|c|c|}
\hline Outcome & $\begin{array}{c}\text { Partial nephrectomy } \\
(n=2503)\end{array}$ & $\begin{array}{c}\text { Radical nephrectomy } \\
(\mathrm{n}=\mathbf{3 1 6 7})\end{array}$ \\
\hline $\begin{array}{l}\text { Chronic kidney disease } \\
\text { \# of events } \\
\text { Hazard ratio* }(95 \% \mathrm{CI})\end{array}$ & $\begin{array}{c}26 \\
0.18(0.11-0.27) \\
\end{array}$ & $\begin{array}{c}223 \\
\text { Reference } \\
\end{array}$ \\
\hline $\begin{array}{l}\text { Renal replacement therapy } \\
\text { \# of events } \\
\text { Hazard ratio }^{ \pm}(95 \% \mathrm{CI})\end{array}$ & $\begin{array}{c}2 \\
0.25(0.06-1.12) \\
\end{array}$ & $\begin{array}{c}13 \\
\text { Reference } \\
\end{array}$ \\
\hline $\begin{array}{l}\text { Myocardial infarction } \\
\text { \# of events } \\
\text { Hazard ratio* }(95 \% \mathrm{CI})\end{array}$ & $\begin{array}{c}42 \\
0.91(0.62-1.34)\end{array}$ & $\begin{array}{c}131 \\
\text { Reference } \\
\end{array}$ \\
\hline $\begin{array}{l}\text { Death from kidney cancer } \\
\text { \# of events } \\
\text { Hazard ratio* }(95 \% \text { CI })\end{array}$ & $\begin{array}{c}36 \\
0.45(0.30-0.65)\end{array}$ & $\begin{array}{c}184 \\
\text { Reference } \\
\end{array}$ \\
\hline
\end{tabular}

*Adjusted for gender, age group, income quintile, Charlson score, year of surgery, tumour size, and histology. ${ }^{ \pm}$Univariate model due to low number of events. CI: confidence interval. 


\begin{tabular}{|c|c|c|c|c|}
\hline \multicolumn{5}{|c|}{$\begin{array}{l}\text { Supplementary Table 1. Multivariable Cox proportional hazard model evaluating the } \\
\text { association between partial or radical nephrectomy and outcomes in patients with pT1a renal } \\
\text { cell carcinoma }\end{array}$} \\
\hline & \multicolumn{4}{|c|}{ Outcome (hazard ratio [95\% confidence interval]) } \\
\hline Predictor & OS & CKD & MI & CSS \\
\hline $\begin{array}{l}\text { Partial } \\
\text { nephrectomy }\end{array}$ & $0.73(0.63-0.84)$ & $0.18(0.11-0.27)$ & $0.92(0.62-1.35)$ & $0.45(0.30-0.65)$ \\
\hline Female gender & $0.81(0.72-0.92)$ & $0.72(0.55-0.94)$ & & $0.65(0.48$ \\
\hline $\begin{array}{l}\text { Age } \\
18-39 \\
40-44 \\
45-49 \\
50-54 \\
55-59 \\
60-64 \\
65-69 \\
70-74 \\
75-79 \\
80+\end{array}$ & $\begin{array}{c}\text { Reference } \\
1.8(0.75-4.6) \\
2.7(1.2-6.2) \\
4.8(2.2-10.4) \\
7.8(3.6-16.8) \\
10.7(5.0-22.9) \\
13.8(6.5-29.4) \\
20.4(9.6-43.4) \\
33.8(15.9-71.8) \\
53.1(24.7-114.1)\end{array}$ & $\begin{array}{c}\text { Reference } \\
0.79(0.36-1.74) \\
1.35(0.70-2.62) \\
2.17(1.16-4.05) \\
2.29(1.24-4.25) \\
2.84(1.54-5.24) \\
2.68(1.44-5.00) \\
2.55(1.30-5.00) \\
3.32(1.64-6.73) \\
3.73(1.59-8.74)\end{array}$ & $\begin{array}{c}\text { Reference } \\
0.95(0.24-3.80) \\
1.46(0.45-4.75) \\
1.43(0.45-4.57) \\
1.88(0.63-5.65) \\
2.21(0.75-6.52) \\
3.77(1.34-10.6) \\
4.28(1.51-12.2) \\
5.27(1.85-15.0) \\
3.27(1.00-10.68)\end{array}$ & $\begin{array}{c}\text { Reference } \\
1.12(0.25-5.03) \\
2.45(0.69-8.71) \\
3.13(0.92-10.6) \\
3.19(0.96-10.6 \\
4.88(1.50-15.9) \\
3.70(1.13-12.1) \\
4.42(1.35-24.5) \\
6.06(1.85-19.9) \\
8.82(2.59-30.1)\end{array}$ \\
\hline $\begin{array}{l}\text { Income quintile } \\
1 \text { (lowest) } \\
2 \\
3 \\
4 \\
5 \text { (highest) }\end{array}$ & $\begin{array}{c}\text { Reference } \\
0.84(0.71-1.00) \\
0.83(0.69-0.98) \\
0.82(0.68-0.98) \\
0.75(0.62-0.89)\end{array}$ & $\begin{array}{c}\text { Reference } \\
1.16(0.78-1.71) \\
1.03(0.68-1.55) \\
1.06(0.70-1.62) \\
0.88(0.58-1.33) \\
\end{array}$ & $\begin{array}{l}\mathrm{R} \\
0.72 \\
0.79 \\
0.70 \\
0.59 \\
\end{array}$ & $\begin{array}{c}\text { Reference } \\
1.27(0.83-1.96) \\
1.42(0.93-2.15) \\
1.31(0.84-2.04) \\
1.10(0.70-1.74) \\
\end{array}$ \\
\hline Charlson score & $1.34(1.30-1.37)$ & $0.84(0.72-0.98)$ & $.96-1.16)$ & 1.37 \\
\hline $\begin{array}{c}\text { Year of surgery } \\
1995-2000 \\
2001-2005 \\
2006-2010 \\
2011-2014 \\
\end{array}$ & $\begin{array}{c}\text { Reference } \\
0.95(0.81-1.11) \\
0.71(0.60-0.83) \\
0.55(0.44-0.69)\end{array}$ & $\begin{array}{l}\text { Reference } \\
1.04(0.72-1.51) \\
1.66(1.18-2.34) \\
2.14(1.35-3.42)\end{array}$ & $\begin{array}{l}\text { Reference } \\
0.86(0.58-1.27) \\
0.55(0.36-0.85) \\
0.59(0.32-1.09)\end{array}$ & $\begin{array}{l}\text { Reference } \\
1.07(0.75-1.54) \\
0.68(0.46-1.00) \\
6.42(3.88-10.61)\end{array}$ \\
\hline Tumor size & $1.09(1.01-1.17)$ & $1.05(0.89-1.24)$ & $1.05(0.86-1.28)$ & $1.18(0.99-1.41)$ \\
\hline $\begin{array}{l}\text { Histology } \\
\text { Clear-cell } \\
\text { Papillary } \\
\text { Chromophobe } \\
\text { Other }\end{array}$ & $\begin{array}{l}\text { Reference } \\
0.96(0.81-1.14) \\
0.80(0.57-1.12) \\
1.22(0.95-1.58)\end{array}$ & $\begin{array}{c}\text { Reference } \\
1.16(0.82-1.65) \\
0.89(0.47-1.70) \\
1.02(0.52-1.99)\end{array}$ & $\begin{array}{c}\text { Reference } \\
0.85(0.55-1.31) \\
1.34(0.65-2.77) \\
0.32(0.10-1.00)\end{array}$ & $\begin{array}{c}\text { Reference } \\
0.96(0.65-1.41) \\
0.38(0.12-1.19) \\
1.95(1.16-3.27)\end{array}$ \\
\hline
\end{tabular}

CKD: chronic kidney disease; CSS: cancer-specific survival; MI: myocardial infarction; OS: overall survival 